Образ матери в творчестве Э. Энрайт: к вопросу о социальном статусе женщины (на примере очерка "Making Babies: Stumbling into Motherhood")

\author{
Кемалова М. Н., Сахапова Ф. Х., Петунина А. Р.
}

Аннотация. Статья посвящена изучению художественного своеобразия очерка современной англоязычной писательницы Энн Энрайт “Making Babies: Stumbling into Motherhood” (2004). Целью исследования является определение особенностей интерпретации образа матери и образа ребенка. Научная новизна настоящего исследования обусловлена тем, что в современном глобальном литературном пространстве вопрос о статусе женщины в ирландском обществе изучен не столь подробно как зарубежными, так и отечественными литературоведами и продолжает вызывать многочисленные дискуссии. В результате исследования было обнаружено, что специфические приемы в очерке Э. Энрайт способствуют созданию принципиально нового образа ирландки в национальной (ирландской) картине.

\title{
EN Mother Image in Anne Enright's Creative Work: Problem of Woman's Social Status (by the Example of the Essay “Making Babies: Stumbling into Motherhood”)
}

\author{
Kemalova M. N., Sakhapova F. H., Petunina A. R.
}

\begin{abstract}
The article is devoted to studying artistic originality of the essay "Making Babies: Stumbling into Motherhood" (2004) by the modern English-speaking writer Anne Enright. The paper aims to reveal specificity of the mother image and the child image interpretation. Scientific originality of the study is conditioned by the fact that the problem of the woman's status in the Irish society has not been previously investigated from the viewpoint of literary criticism; this issue remains hotly debated and attracts special attention of foreign and domestic literary critics. Relying on the findings, the researchers conclude that Enright's artistic techniques promote formation of a cardinally new Irish woman image in the Irish national worldview.
\end{abstract}

\section{Введение}

Довольно долгое время творческий путь Энн Терезы Энрайт (англ. Anne Teresa Enright, 1962) не представлял для литературоведов и критиков исследовательского интереса, имя писательницы не пользовалось признанием в Ирландии, не говоря уже о популярности за ее пределами. С присуждением Букеровской премии писательнице в 2007 году за роман “Тhe Gathering” ситуация кардинально изменилась. Интерес к личности и творчеству Энн Энрайт, представленного романами, рассказами, эссе, публицистикой, был обнаружен не только со стороны исследователей-литературоведов, но и специалистов из совершенно других, не смежных с литературой областей, например, экономистов, социологов и психологов. Это объясняется тем, что Энрайт чрезвычайно правдиво рассказывает о сторонах ирландской действительности, например, посткельтском периоде, финансовом кризисе и безработице, а также личных проблемах граждан. Э. Энрайт создала ряд произведений, оставивших заметный след не только в истории ирландской литературы, но и европейской, мировой в целом.

Актуальность исследования определяется тем, что проблема правового статуса женщины в ирландском обществе, в котором все еще довлеют многочисленные стереотипы, гласные и негласные запреты, в современном глобальном литературном пространстве продолжает вызывать многочисленные дискуссии.

Цель работы конкретизируется в следующих задачах:

- раскрыть авторскую позицию по проблеме статуса женщины в современном ирландском обществе;

- выявить особенности интерпретации образа матери;

- рассмотреть специфику интерпретации образа ребенка. 
В соответствии с характером поставленных задач в работе используется метод целостного анализа литературного произведения.

Теоретической базой данной статьи являются положения, выдвинутые в трудах зарубежных исследователей, таких как М. Кеннеди (англ. М. Kennedy) [7], П. Кофлэн (англ. P. Coughlan) [2].

Практическая значимость работы состоит в том, что результаты исследования могут быть применены для дальнейшего изучения творчества Энн Энрайт в частности, а также общих вопросов современного состояния и тенденций развития ирландской литературы в целом. Материалы исследования также могут быть использованы в вузовских курсах истории мировой литературы XX века, спецкурсах, посвященных современной ирландской словесности и проблемам современного ирландского романа.

\section{Авторская позиция по проблеме статуса женщины в современном ирландском обществе}

Энн Энрайт даёт многочисленные интервью различным газетам и журналам (The Guardian, The Sunday Business Post, etc.), участвует в теле-, радиопрограммах, читает лекции в университетах, проявляя свои позиции по тому или иному общественно-политическому вопросу, волнующему ирландское общество на рубеже XX-XXI вв. [4]. Размышления Э. Энрайт о сторонах ирландской действительности находят отражение в её произведениях, лейтмотивом в которых проходит призыв переосмыслить или вовсе отказаться от некоторых косных стереотипов, норм прошлого, присущих сознанию современного ирландского общества. Так, в произведении “Making Babies: Stumbling into Motherhood” в центре конфликта находится вопрос о статусе современной женщины-матери.

Очерк «Создавая детей: долгий путь к материнству» (утверждённого перевода на данный момент нет) представляет собой своеобразный призыв переосмыслить образ современной женщины-матери. Энн Энрайт, осознавая, что затрагивает один из главных классических образов, присущих мировой литературе в целом, в первой главе “Apologies All Around” («Повсеместные извинения») объясняет, что хотела лишь открыто рассказать о своем опыте материнства.

"Speech is a selfish act, and mothers should probably remain silent...So I'd like to say sorry to everyone in advance. Sorry. Sorry. Sorry. Sorry. I'd like to apologise to all those people who find the whole idea of talking about things as opposed to just getting on with them mildly indecent, or provoking - I do know what they mean...” [5, p. 1]./ «Речь - это эгоистичный поступок, и мамам, вероятно, следовало бы помолчать... Поэтому я хотела бы заранее извиниться перед всеми. Извините. Извините. Извините. Извините. Я хотела бы извиниться перед всеми теми людьми, которые считают, что сама идея говорить о вещах, с которыми нужно быть в согласии, слегка неприлична или провоцирует - я знаю, что они имеют в виду...» (здесь и далее перевод выполнен авторами статьи. - М. К., Ф. С., А. П.).

Также, писательница объясняет причину своих довольно вольных, смелых высказываний, резкий тон и новаторский стиль произведения в целом.

"This might account for any wildness of tone. The pieces were typed fast. They were written to the sound of a baby's sleeping breath. Some were assembled, later, from notes, but I have tried to keep the flavor of the original scraps... I wanted to say something about the anxiety of reproduction, the oddness of it, and how it feels like dying, pulled inside out” [Ibidem, p. 3]. / «Это могло бы объяснить всю резкость тона. Главы печатались быстро. Они были написаны под звук дыхания спящего ребенка. Некоторые были собраны позже, из заметок, но я постаралась сохранить их оригинальность, первозданный вид... Я хотела рассказать, каково это - быть родителем, о странности этой затеи, и о том, как роды похожи на смерть, когда ты словно вывернута наизнанку».

Э. Энрайт в анализируемом очерке отмечает, что беременность и материнство не всегда сопряжены только с положительными эмоциями, как это преподносится в ярких рекламах. Писательница рассуждает о пагубном влиянии навязанного стереотипа о «вечно радующейся» матери на психику женщины, находящейся в послеродовой депрессии. Важно подчеркнуть, что Э. Энрайт предпринимает попытку не противопоставить, а ввести новый, иной образ матери в один ряд с классическим, ассоциируемым в ирландском обществе с образом Девы Марии.

Следует отметить, что четко обозначить жанр произведения «Создавая детей: долгий путь к материнству» представляется довольно непростой задачей для исследователей. Это полухудожественный и в то же время полудокументальный очерк, героями которого являются реальные люди, в частности сама Энн Энрайт, ее муж Мартин и их новорожденная дочь. Данный очерк, в котором насчитывается всего сто девяносто девять страниц, можно отнести к жанру «малой» прозы (англ. flash prose) [3].

Произведение представляет собой своеобразное руководство по вопросам ухода за детьми, свод предостережений и правил, которого нужно придерживаться матерям, а также дневник, в котором Э. Энрайт открыто делится своими внутренними переживаниями и проблемами, с которыми ей пришлось столкнуться и преодолеть во время беременности и в первые годы материнства. В главах, объем которых варьируется от нескольких строк до десяти страниц, поднимаются злободневные вопросы, возникшие в определенной гражданской нравственной среде современного ирландского общества, такие как: статус ирландки, отношение общества к женщинам в положении в прошлом и настоящем, обязанности матери по отношению к своему ребенку, влияние феминизма на мировоззрение современной женщины и т.д.

В очерке «Создавая детей: долгий путь к материнству» Энн Энрайт на первый план вынесено научнопублицистическое исследование конкретной актуальной проблемы или проблем, заявленных выше, создается некий развернутый образ самой ситуации, а не делается акцент на личности как таковой, ее психоэмоциональном 
состоянии, внутреннем мире. Таким образом, очерк Э. Энрайт «Создавая детей: долгий путь к материнству» представляет собой новаторский концептуальный авторский монолог с частыми ретроспекциями и лирическими отступлениями.

\section{Статус женщины в Ирландии в прошлом и настоящем}

П. Кофлэн (англ. Р. Coughlan) в статье “Irish Literature and Feminism in Postmodernity” отмечает, что ранее актуальные социальные проблемы (например, факты домашнего насилия, растления малолетних священнослужителями и т.д.) намеренно не освещали, так как, безусловно, открытое обсуждение могло сподвигнуть без того неустойчивое «фрагментарное» ирландское общество на акции протеста и даже бунты [2, p. 177]. Проблема послеродовой депрессии также входила в круг запретных тем. Внутренний эмоциональный фон женщины не представлял интереса и важности для ортодоксального общества того времени. Следовательно, женщина не могла заявить о самом факте существования данной проблемы, так как в противном случае ее слова были бы истолкованы неверно. Ситуация кардинально изменилась в 1970 году, когда развивающееся движение феминизма в Ирландии предоставило каждой женщине право рассказать открыто и без боязни осуждения о своих тщательно скрываемых переживаниях и страхах. Две наиболее влиятельные неполитические организации, Ассоциация ирландских селянок и Ассоциация ирландских домохозяек (англ. "Irish Countrywomen's Association” and “Irish Housewives’ Association”), а также сама президент Мэри Робинсон в 1990 году выступили с инициативой пересмотреть принятое в обществе уничижительное отношение к женщине и даже позволить ей участвовать в политической жизни страны [10, p. 96]. Образ женщины был пересмотрен на законодательном уровне, доказательством чему служат статьи конституции, в которых прописаны права и обязанности каждого гражданина.

Таким образом, статус женщины значительно возрос, что со временем предоставило возможность писательницам, не переступая общепринятые нормы морали, иной раз вести открытый диалог с согражданами о насущных проблемах, волнующих современное ирландское общество, что ранее было невозможно [6, р. 134]. Целая плеяда ирландских англоязычных писательниц, лауреатов многих престижных литературных премий (Эмма Донохью (р. 1969), Анна Бернс (р. 1969), Салли Руни (р. 1991) и т.д.) продолжает писать о насущных проблемах и сторонах ирландской действительности, рассуждать о судьбе родной страны. Магистральной темой в их творчестве проходит тема социального статуса женщины в современных реалиях. Зачастую творческая энергия писательниц расценивается исследователями и критиками как некое тяготение к феминистическому течению в литературном пространстве.

\section{Образ матери и образ ребенка: особенности интерпретации}

Исследователь творчества Энн Энрайт М. Кеннеди (англ. М. Kennedy) в статье, посвященной женским образам, представленным писательницей, заявляет о том, что ключевым образом в ее произведениях зачастую выступает женщина (иногда и с некоторыми психическими расстройствами), которая может испытывать амбивалентные чувства к своим детям, что приводит к непониманию и осуждению со стороны ортодоксально настроенного общества [7, p. 4]. Э. Энрайт вводит образ женщины, находящейся в послеродовой депрессии, прототипом которой является она сама. Также автор намеренно создает две враждующие между собой зрелые личности, мать и ребенка, что является вызовом нормам общественной морали и принципиально новым для современной ирландской прозы в целом.

Новорожденная дочь писательницы представлена на страницах очерка «Создавая детей: долгий путь к материнству» в образе зрелой личности, своеобразной соперницы матери, хотя девочке нет еще и полугода. «Взрослый» ребенок осознает и анализирует все происходящее вокруг, выбирая для себя наиболее выгодные схемы поведения, исходя из конкретной ситуации. Например, Энн Энрайт характеризует ее следующим образом:

"She is more imperious when her father picks her up. She sits in his arms and looks over at me as if to say, So who are you? The baby sits in her father's arms and looks over at me, like I am a stranger, walked in off the street. Oh, that blank stare. It makes me laugh, and go over to her, and take her back from him. Silly baba” [5, p. 56-57]. / «Она в наивысшей степени надменна, когда находится у папы на руках. Сидя, она бросает на меня взгляд, как бы спрашивая: “Ну и кто же ты?” Ребёнок сидит на руках папы и смотрит на меня, словно я незнакомка с улицы. Ох уж этот пустой взгляд. Он заставляет меня нервно засмеяться, подойти и забрать её у него. Глупый папочка».

Э. Энрайт, описывая ребенка, называет его «пришельцем» (англ. alien), «Дракулой» (англ. Dracula) и «чудовищем» (англ. beast) [8]. Данное семантическое ядро вызывает ассоциацию с рядом отрицательных героев, персонажей и интенсифицирует гротескно изображенную вражду матери и ребенка. Также писательница в главе “Nine Months” («Девять месяцев») представила дневниковые записи, написанные параллельно от лица матери “Regression (me)”, то есть регрессия, упадок сил, и маленькой девочки “Development (me)”, то есть развитие и рост; всего описано девять месяцев из жизни матери и дочери [Ibidem, p. 48]. Как можно заметить, образ ребенка, введенный Э. Энрайт, не имеет ничего общего с образом невинного, беззащитного существа, то есть классическим образом ребенка в мировой литературе.

Тема родительской ответственности проявляется в произведении как имплицитно, так и эксплицитно. В одной из глав приведен список “How to Kill Your Baby”, то есть дословно «Как убить своего ребенка» [9], в котором рассмотрено все то, что опасно и может причинить вред маленькому члену семьи. В конце списка, который представлен в виде пронумерованного столбца, писательница с сожалением заявляет, что вне 
зависимости от того, что вызовет недовольство у ребенка, даже если это был несчастный случай, мать всегда объявляется убийцей, а ребенок, прекрасно осознавая это, пользуется правом делать все, что захочется, раз за разом «выходя сухим из воды». Энн Энрайт, приводя подобные списки с лексическими единицами «убить», «убийца», не стремится показать кого-то из героев положительным или отрицательным, а предоставляет право читающей публике задуматься о той ответственности, что ложится на мать.

Образ матери в произведении Э. Энрайт самобытен, представлен в сравнении с другими образами/символами. Писательница заявляет, что «беременная женщина является достоянием общества», тогда как в жизни ей не на кого опереться. Символично сравнение беременной женщины с трансформировавшимся в жука Грегором, героем повести Ф. Кафки. Приведем данную реминисценцию далее:

"If Kafka had been a woman, then Gregor Samsa would not have turned into an insect, he would not have had to. Gregor would be Gretel and she would wake up one morning pregnant. She would try to roll over and discover she was stuck on her back. She would wave her little hands uselessly in the air” [5, p. 17]. / «Если бы Кафка был женщиной, то Грегор Замза не превратился бы в насекомое, ему не пришлось бы этого делать. Грегор был бы Гретель, и однажды утром она бы проснулась беременной. Она попробовала бы перевернуться и обнаружила, что лежит на спине. Она беспомощно махала бы в воздухе своими маленькими ручонками».

В очерке «Создавая детей: долгий путь к материнству» проведены яркие аналогии между женщиной и предметами. Писательница подчеркивает, что мать словно фотоаппарат выдает заветную копию (фотографию) всем членам семьи, а ее саму забывают и как ненужный фотоаппарат забрасывают в угол до следующего раза. Женское тело представлено некой ареной для ребенка, который может делать все, что ему/ей захочется, и за это ему не придется отвечать.

Несмотря на акцентирование внимания читателей более на реальной и не столь приятной стороне беременности и материнства, порою утрированной, в «Создавая детей: долгий путь к материнству» представлены искренние нежные сцены любви матери к ребёнку:

"At nine months, the baby puts her head in a pot and says, Aaah Aaah Aaah. She says it very gently and listens to the echo. She has discovered this all by herself. By way of celebration, I put my own head into the pot and say, Aaah Aaah Aaah. Then she does it again. Then I do it again. And so on” [Ibidem, p. 66]. / «В девять месяцев ребенок прислоняет голову к чайнику и говорит: “Ааа Ааа Ааа”. Она говорит это очень мягко и прислушивается к эху. Это ее открытие. Празднуя это, я тоже прислоняю голову к чайнику и говорю: “Ааа Ааа Ааа”. Затем она делает это снова. Затем я делаю это снова. И так далее»;

"I pick the baby up and we look in the wardrobe mirror, which has always been for her a complicated delight: What is it? It's a baby! She smiles, it smiles back! (Complication upon complication! It's me! It's me! she says, and all her synapses, as I imagine, going ping! ping! ping!) She sees me smiling at her in the mirror” [Ibidem, p. 68]. / «Я беру ребенка на руки, и мы смотрим в зеркало гардероба, что всегда было для нее супернаслаждением: “Что это? Это же ребенок! Я улыбаюсь, и она улыбается в ответ!” (Просто супернаслаждение! Это я! Это я! - говорит она, и вся она, как я себе могу представить, начинает ликовать внутри! Ура! Ура!). Она видит, как я улыбаюсь ей в зеркале».

Таким образом, Э. Энрайт, рассказав искренне о своих чувствах к ребенку в очерке «Создавая детей: долгий путь к материнству», призывает современное общество осознать всю важность и ответственность материнства.

\section{Заключение}

Итак, на основании проведённого анализа очерка «Создавая детей: долгий путь к материнству» Энн Энрайт мы приходим к следующим выводам. Интерпретация образа матери и образа ребенка в произведении явилась принципиально новыми для современной ирландской прозы. Писательница, следуя постмодернистской тенденции отрицания и разрушения привычного образа (что в ряде литератур произошло ранее), предпринимает попытку переосмысления образа современной ирландки в национальной литературе, тем самым не противопоставляя, а вводя его в один ряд с классическим. Новый образ женщины обладает уже более значимым социальным статусом и не скован общественными стереотипами и закостенелыми нормами, по сравнению с более ранним периодом в истории страны. Э. Энрайт объяснила на своём примере, что противоречивые чувства к ребёнку, особенно в первые месяцы его жизни, не являются выходящими за пределы нормы и ни в коем случае не подтверждают отсутствия материнских чувств у женщины. Принципиально новые образы писательницы, прототипами которых явились она сама, ее муж и дочь, были реконструированы с учетом действительности современного ирландского общества и представляют научный интерес для европейской, мировой литературы в целом.

Перспективы дальнейшего исследования связаны с изучением других художественных текстов Энн Энрайт в сопоставлении с произведениями, написанными в тот же период ирландскими англоязычными авторами.

\section{Список источников}

1. Constitution of Ireland [Электронный ресурс]. URL: http://www.irishstatutebook.ie/eli/cons/en (дата обращения: 08.03.2021).

2. Coughlan P. Irish Literature and Feminism in Postmodernity // Hungarian Journal of English and American Studies. 2004. Vol. 10. № 1/2. P. 175-202. 
3. Dictionary of literary terms \& literary theory / preface by J. A. Cuddon. 3rd ed. L.: Penguin Books, 1992. $991 \mathrm{p}$.

4. Enright A. Diary [Электронный ресурc]. URL: https://www.lrb.co.uk/v33/n04/anne-enright/diary (дата обращения: 08.03.2021).

5. Enright A. Making Babies: Stumbling into Motherhood. L.: Vintage, 2005. 195 p.

6. Gender and Sexuality in Modern Ireland / ed. by A. Bradley, M. G. Valiulis. Amherst: University of Massachusetts Press, 1997. $324 \mathrm{p}$.

7. Kennedy M. Freeing the Smothered (M)other: The Refocalisation of the Reluctant Mother in Modern Irish Society as Evinced through the Works of Anne Enright [Электронный ресурc]. URL: http://www.otherness.dk/fileadmin/ www.othernessandthearts.org/Publications/Journal_Otherness/Otherness_Essays_and_Studies_3.2/The_Smothere d_Mother_-_Michelle_Kennedy.pdf (дата обращения: 08.03.2021).

8. Longman Dictionary of Contemporary English [Электронный ресурc]. URL: http://www.ldoceonline.com (дата обращения: 08.03.2021).

9. New English-Irish Dictionary [Электронный ресурс]. URL: https:/www.focloir.ie/ (дата обращения: 08.03.2021).

10. O'Brien A. M. Locating women within the Irish Department of External Affairs: A case study of Irish women at the League of Nations and United Nations, 1923-76 // Irish Historical Studies. 2019. Vol. 43. Issue 163. P. 94-110.

\section{Информация об авторах | Author information}

RU Кемалова Миляуша Назимовна ${ }^{1}$, к. филол. н.

Сахапова Фарида Ханифовна'라 к. пед. н.

Петунина Айгуль Рамилевна

1,2,3 Набережночелнинский институт (филиал) Казанского (Приволжского) федерального университета

EN Kemalova Milyausha Nazimovna ${ }^{1}, \mathrm{PhD}$

Sakhapova Farida Hanifovna ${ }^{2}$, PhD

Petunina Aigul Ramilevna ${ }^{3}$

${ }^{1,2,3}$ Naberezhnye Chelny Institute of Kazan (Volga Region) Federal University

${ }^{1}$ scarlett_08@list.ru, ${ }^{2}$ sakh.farida@gmail.com, ${ }^{3}$ arrrctica91@gmail.com

\section{Информация о статье | About this article}

Дата поступления рукописи (received): 10.03.2021; опубликовано (published): 30.04.2021.

Ключевые слова (keywords): ирландская литература; Энн Энрайт; образ матери; образ ребенка; Irish literature; Anne Enright; mother image; child image. 